\title{
Some Observations on a Streptomycin-dependent Strain of Staphylococcus aureus
}

\author{
By G. E. FOLEY AND H. SHWACHMAN \\ The Division of Laboratories and Research, The Children's Medical Centre, \\ and the Department of Pathology and Pediatrics, Harvard Medical School, \\ Boston, Massachusetts
}

SUMMARY: Variants whose growth was either dependent upon or enhanced by streptomycin appeared spontaneously during a sensitivity titration of a strain of Staphylococcus aureus isolated from a nose and throat culture. In addition to these variants, multiple single colony strains from the original culture exhibited a wide range of susceptibility to streptomycin. The variability after exposure to streptomycin in the laboratory was no greater than that exhibited by the original isolates.

The mechanism by which these variants utilize streptomycin is not yet known. Streptomycin inactivated by semicarbazide or L-cysteine did not support or enhance growth. The acquisition of the ability to utilize streptomycin had no measurable effect on the other biochemical characteristics investigated.

When large inocula of the dependent variant were planted on streptomycin-free agar, a few colonies appeared after prolonged incubation. The cells of such colonies underwent a profound morphologic change not unlike the production of 'large bodies' which occurs in several species of bacilli. The progeny of such colonies were of normai morphology and either resistant or susceptible to streptomycin but were no longer dependent on it.

Survival of the variants in chick embryos, except in those instances where mutation occurred, was dependent upon the presence of streptomycin. These variants were mouse avirulent, even in the presence of hog mucin in addition to streptomycin.

The purpose of this paper is to describe a strain of Staphylococcus aureus in which 'streptomycin-dependent' and 'streptomycin-enhanced' variants appeared spontaneously during a routine streptomycin sensitivity titration.

\section{Qrigin of variants}

The strain of Staph. aureus was isolated from the nasopharynx of a patient with pancreatic fibrosis who had not received streptomycin therapy before the isolation of the culture. When examined for streptomycin sensitivity by a tube-titration method (Price, Nielsen \& Welch, 1946), growth was obtained after $24 \mathrm{hr}$. at $37^{\circ}$ only in the streptomycin-free control and in those tubes containing 0.03125 and $0.0625 \mathrm{mg}$. streptomycin sulphate per $\mathrm{ml}$. The titration was repeated, with essentially similar results, i.e. some growth in the streptomycin-free control tube and in the tube containing $0.0625 \mathrm{mg}$. streptomycin sulphate per ml. Serial subculture from the streptomycin-free control and the tube containing $0.0625 \mathrm{mg}$. streptomycin sulphate per ml. to tryptic digest agar with and without streptomycin resulted in the isolation of two distinct variants, one almost completely dependent upon streptomycin for growth ('D' variant), and the other (' $E$ ' variant) enhanced in growth by streptomycin. 


\section{Sensitivity of single colony strains}

Multiple single colony fishings were made from the original blood agar plate to tryptic digest broth and to tryptic digest agar, the latter with and without streptomycin sulphate $(0.0625 \mathrm{mg} . / \mathrm{ml}$.). Eleven of fifteen such isolates proved on subculture to be non-dependent and non-enhanced, while a streptomycindependent variant was derived from the progeny of one and streptomycinenhanced variants were derived from the progeny of three single colonies.

The broth cultures of the eleven non-dependent, non-enhanced single colony isolates were plated on tryptic digest agar and a number of single colony isolations again made in broth, incubated, plated and in turn fished to broth. By this procedure, forty-four single colony strains were derived from the eleven original single colony strains. The streptomycin sensitivity of each was determined by tube titration (Table 1). The single colonies isolated from the original blood agar plate varied markedly in their sensitivity to streptomycin. The broth culture progeny of these single colonies, when fished from tryptic digest plates, again showed striking dissimilarity to their parent colonies as regards streptomycin sensitivity through the second and third subcultures.

Table 1. Streptomycin sensitivities of single colony isolates of Staphylococcus aureus as indicated by a minimal inhibitory dose of streptomycin sulphate (M.I.D.)

\begin{tabular}{|c|c|c|c|c|c|}
\hline \multicolumn{2}{|c|}{$\begin{array}{l}\text { First subculture original } \\
\text { single colony isolates }\end{array}$} & \multicolumn{2}{|c|}{ Second subculture } & \multicolumn{2}{|c|}{ Third subculture } \\
\hline $\begin{array}{l}\text { No. } \\
\text { isolates }\end{array}$ & $\begin{array}{l}\text { M.I.D. } \\
\text { (mg./ml.) }\end{array}$ & $\begin{array}{l}\text { No. } \\
\text { isolates }\end{array}$ & $\begin{array}{l}\text { M.I.D. } \\
\text { (mg./ml.) }\end{array}$ & $\begin{array}{l}\text { No. } \\
\text { isolates }\end{array}$ & $\begin{array}{c}\text { M.I.D. } \\
\text { (mg./ml.) }\end{array}$ \\
\hline \multirow[t]{3}{*}{$\mathbf{1}$} & $1 \cdot 0$ & $\mathbf{3}$ & $0 \cdot 125$ & $\mathbf{1}$ & 0.03125 \\
\hline & & 6 & 0.0625 & $\mathbf{3}$ & $0 \cdot 016$ \\
\hline & & $\mathbf{1}$ & $0 \cdot 03125$ & $\mathbf{1}$ & $0 \cdot 008$ \\
\hline $\mathbf{3}$ & 0.5 & & & & \\
\hline \multirow[t]{6}{*}{4} & $0 \cdot 25$ & $\mathbf{3}$ & $\mathbf{0 \cdot 2 5}$ & $\mathbf{1}$ & $\mathbf{2 \cdot 0}$ \\
\hline & & $\mathbf{2}$ & $0 \cdot 125$ & 4 & $1 \cdot 0$ \\
\hline & & $\mathbf{1}$ & 0.0625 & & \\
\hline & & $\mathbf{1}$ & 0.03125 & & \\
\hline & & $\mathbf{I}$ & 0.016 & & \\
\hline & & $\mathbf{1}$ & $0 \cdot 008$ & & \\
\hline 1 & $0 \cdot 125$ & & & & \\
\hline 1 & 0.0625 & & & & \\
\hline$y$ & 0.016 & 2 & 0.25 & 5 & 0.016 \\
\hline & & 3 & $0 \cdot 125$ & & \\
\hline & & 2 & 0.0625 & & \\
\hline & & $\mathbf{3}$ & 0.03125 & & \\
\hline 11 & & 29 & & 15 & (55) \\
\hline
\end{tabular}

Streptomycin sensitivity titrations also were done on single colony isolates derived from a culture which had grown in the presence of a known concentration of streptomycin sulphate. The last tubes in which growth occurred in two of the streptomycin titrations listed in Table 1 were plated on tryptic digest agar, incubated and single colony subcultures made in tryptic digest broth. The last tubes showing growth in streptomycin sensitivity titrations made on 
these isolates were then treated in a similar manner. The data obtained from the study of fifty-six single colony isolates derived from the original in this manner are summarized in Table 2.

Table 2. Streptomycin sensitivities of single colony isolates of Staphylococcus aureus after exposure to streptomycin at different concentrations (mg./ml.)

\begin{tabular}{|c|c|c|c|c|c|c|}
\hline \multirow{2}{*}{$\begin{array}{l}\text { Single colony } \\
\text { isolates from } \\
\text { culture exposed } \\
\text { to streptomycin } \\
(\mathrm{mg} . / \mathrm{ml} .)\end{array}$} & \multicolumn{2}{|c|}{ First subculture } & \multicolumn{2}{|c|}{ Second subculture } & \multicolumn{2}{|c|}{ Third subculture } \\
\hline & $\begin{array}{c}\text { No. } \\
\text { isolates }\end{array}$ & $\begin{array}{l}\text { Grew in* } \\
\text { (mg./ml.) }\end{array}$ & $\begin{array}{c}\text { No. } \\
\text { isolates }\end{array}$ & $\begin{array}{c}\text { Grew in } \\
(\mathrm{mg} . / \mathrm{ml} .)\end{array}$ & $\begin{array}{l}\text { No. } \\
\text { isolates }\end{array}$ & $\begin{array}{l}\text { Grew in } \\
(\mathrm{mg} . / \mathrm{ml} .)\end{array}$ \\
\hline \multirow{4}{*}{$\begin{array}{c}0.25 \\
(\text { inhibited by } 0.5) \dagger\end{array}$} & $\mathbf{1}$ & $\mathbf{2 \cdot 0}$ & $\mathbf{5}$ & $1 \cdot 0$ & $\mathbf{1}$ & $1 \cdot 0$ \\
\hline & & & 2 & 0.0625 & 2 & 0.25 \\
\hline & & & 1 & 0.016 & $\overline{1}$ & $0 \cdot 125$ \\
\hline & & & 1 & 0.008 & 1 & 0.0625 \\
\hline & 4 & $\mathbf{2 \cdot 0}$ & 6 & $0 \cdot 03125$ & 5 & 0.016 \\
\hline \multirow[t]{6}{*}{$($ inhibited by $0 \cdot 125) \dagger$} & $\mathbf{1}$ & $\mathbf{2 \cdot 0}$ & 2 & 0.016 & & \\
\hline & $\mathbf{3}$ & $1 \cdot 0$ & $\mathbf{1}$ & 0.008 & & \\
\hline & & & $\mathbf{1}$ & $0 \cdot 004$ & & \\
\hline & $\mathbf{3}$ & 0.5 & 4 & $0 \cdot 03125$ & 1 & $0 \cdot 125$ \\
\hline & & & 6 & $0 \cdot 016$ & 2 & 0.03125 \\
\hline & & & & & 2 & 0.016 \\
\hline Total & 12 & & 29 & & 15 & (56) \\
\hline
\end{tabular}

It is apparent that exposure to a given concentration of streptomycin did not fix the sensitivity of this strain at or above that concentration, since there was as much fluctuation in streptomycin sensitivity among these single colony isolates as was observed among those derived from the original blood agar plate which had not been exposed to streptomycin. These isolates were uniformly resistant to penicillin (more than $2.5 \mu \mathrm{g} . / \mathrm{ml}$.) but sensitive to both bacitracin (0.5 $\mu$ g.) (Johnson, Anker \& Meleney, 1945) and aureomycin (0.5 $\mu$ g.) (Duggar, 1948). Penicillinase (Bondi \& Dietz, 1944) was produced by all isolates tested.

A second nasopharyngeal culture was obtained from the same patient 2 months later, after 3 weeks of aerosol therapy which consisted of three or four daily inhalations of penicillin (100,000 units) and streptomycin (0.2 mg.). Similar studies on this strain of Staphylococcus aureus gave essentially the same results.

\section{Effect of streptomycin on the $D$ and $E$ variants}

The $D$ variant grew in media containing as little as $0.00005 \mathrm{mg}$. or as much as $50 \mathrm{mg}$. streptomycin sulphate per $\mathrm{ml}$. Growth was sparse and sporadic in concentrations less than $0.00005 \mathrm{mg} . / \mathrm{ml}$., and concentrations of more than $50 \mathrm{mg} . / \mathrm{ml}$. were inhibitory. The $D$ variant, when planted heavily in streptomycin-free media and incubated for relatively long periods of time, usually yielded a slight amount of growth, for example, a streptomycin-free tryptic digest plate streaked with a $2 \mathrm{~mm}$. loopful of colonial growth usually grew ten or twenty colonies after $\mathbf{4 8 - 7 2} \mathrm{hr}$. incubation at $37^{\circ}$. (Similar inocula streaked 
on streptomycin tryptic digest agar resulted in a heavy, confluent growth after $24 \mathrm{hr}$. at $37^{\circ}$.) The progeny of the colonies from the streptomycin-free plate were streptomycin-sensitive or resistant, but none was streptomycin-dependent.

Similar experiments done with the $\mathbf{E}$ variant yielded comparable results. The range of streptomycin concentrations which enhanced growth and the inhibitory dose were essentially the same as those supporting and inhibiting the growth of the $D$ variant

\section{In vivo experiments}

The dependence of the $\mathbf{D}$ variant on streptomycin raised the question as to whether or not this strain could survive in vivo in the absence of streptomycin.

Ten-day chick embryos were prepared by the usual window method and treated with $2.5 \mathrm{mg}$. streptomycin sulphate on the chorioallantoic membrane. Similar numbers of treated and control embryos were then inoculated on the chorioallantoic membrane with $0 \cdot 1 \mathrm{ml} .\left(c .4 \cdot 5 \times 10^{6}\right.$ cells $)$ of a saline suspension of the $\mathbf{D}$ variant prepared from a tryptic digest streptomycin agar plate. The eggs were incubated at $37^{\circ}$, examined daily by smear and plated at $48 \mathrm{hr}$. intervals on tryptic digest agar with and without streptomycin to determine the viability of the staphylococci seen by smear.

Although different experiments showed some individual variation, the overall results were similar to those summarized in Table 3. Streptomycin appeared to be essential for the survival and growth of the $D$ variant in 10-day chick embryos, except in those instances in which a non-dependent mutant appeared after prolonged incubation. It is interesting to note that the $D$ variant gave rise to non-dependent mutants in the chick embryo as well as in artificial media.

Table 3. Effect of streptomycin on survival of the $D$ variant of Staphylococcus aureus in chick embryos

\begin{tabular}{|c|c|c|c|c|}
\hline \multirow[b]{2}{*}{$\begin{array}{l}\text { Incubation } \\
\text { period (hr.) }\end{array}$} & \multicolumn{2}{|c|}{ Streptomycin, 2.5 mg. } & \multicolumn{2}{|c|}{ No streptomycin } \\
\hline & $\begin{array}{l}\text { Gram stain } \\
\text { showed }\end{array}$ & Cultures & Gram stain showed & Cultures \\
\hline 24 & Heavy growth & 一 & Few cells, intracellular & - \\
\hline 48 & Heavy growth & $\begin{array}{c}\text { STDA } 4+ \\
\text { TDA } 0\end{array}$ & Few cells, intracellular & $\begin{array}{r}\text { STDA } 0 \\
\text { TDA } 0\end{array}$ \\
\hline 72 & Heavy growth & - & Few cells, intracellular & - \\
\hline 96 & Heavy growth & $\begin{array}{c}\text { STDA } 4+ \\
\text { TDA } 0\end{array}$ & Few cells, intracellular & $\begin{array}{l}\text { STDA } 0 \\
\text { TDA } 1+\end{array}$ \\
\hline \multicolumn{5}{|c|}{$\begin{aligned} \text { TDA } & =\text { tryptic digest agar. } \\
\text { STDA } & =\text { tryptic digest agar }+ \text { streptomycin sulphate, } 0 \cdot 1 \mathrm{mg} \cdot / \mathrm{ml} . \\
4+ & =\text { more than } 100 \text { colonies. } \\
1+ & =\text { less than } 20 \text { colonies. }\end{aligned}$} \\
\hline
\end{tabular}

The $\mathbf{D}$ and $\mathbf{E}$ variants were avirulent for mice, even when injected intraperitoneally with hog mucin as well as streptomycin. The non-dependent, non-enhanced isolates of the strain from which these were derived were also mouse avirulent. 


\section{Substitution for streptomycin}

Dihydrostreptomycin sulphate (Bartz, Controulis, Crooks \& Rebstock, 1946) could be substituted for streptomycin with either the D or E variant. Streptomycin sulphate inactivated by semicarbazide hydrochloride (Rake \& Donovick, 1946) or by L-cysteine hydrochloride (Denkelwater, Cook \& Tishler, 1945) did not support growth of the $\mathbf{D}$ variant or enhance the growth of the $\mathbf{E}$ variant, when tested in tryptic digest broth and agar or sodium thiolacetate broth.

Ammonium, ferric, or adenine sulphate, sodium thiolacetate, L-cystine, L-cysteine, guanidine carbonate, guanine hydrochloride, 2, 4, 5-triamino-6hydroxypyrimidine and $i$-inositol, singly or in their various combinations in concentrations of 30,60 and $120 \mu \mathrm{g} . / \mathrm{ml}$. medium could not be substituted for streptomycin with either the $\mathbf{D}$ or $\mathbf{E}$ variant. Similarly, the addition of trace elements, $\mathrm{Fe}, \mathrm{Mg}, \mathrm{Mn}, \mathrm{Cu}, \mathrm{Zn}$, and $\mathrm{Co}$ (as sulphate or chloride) or vitamins, calcium pantothenate, aneurin hydrochloride, nicotinic acid, riboflavin, pyridoxin, folic acid and biotin, in concentrations of as much as $10 \mu \mathrm{g} . / \mathrm{ml}$. , did not support growth of the $D$ variant or enhance growth of the $E$ variant. Crystalline penicillin G, bacitracin sulphate or aureomycin could not be substituted for streptomycin in similar concentrations. Bacitracin and aureomycin, when titrated in the presence of $0 \cdot 1 \mathrm{mg} . / \mathrm{ml}$. of streptomycin, inhibited both the $\mathbf{D}$ and $\mathbf{E}$ variants.

\section{Biochemical studies}

The biochemical characteristics of the $\mathbf{D}$ and $\mathbf{E}$ variants were determined in the presence of $0.1 \mathrm{mg}$. streptomycin sulphate per $\mathrm{ml}$. of the various media. The non-dependent, non-enhanced variants were tested in the same media without streptomycin for comparison. All strains fermented glucose, maltose, mannitol, lactose and sucrose (but not xylose or dulcitol), liquefied gelatin and split urea.

It has been observed that penicillin and streptomycin delay or inhibit the formation of plasma clots by staphylocoagulase (Agnew, Kaplan \& Spink, 1947). The ability of the $D$ and $E$ variants to coagulate sterile human plasma in the presence of streptomycin was determined by the addition of $0.5 \mathrm{ml}$. of plasma to $0.5 \mathrm{ml}$. of tryptic digest broth containing concentrations of streptomycin sulphate such that the final concentration after the addition of plasma ranged from $25 \mathrm{mg}$. to $0.00005 \mathrm{mg}$. $/ \mathrm{ml}$. Each tube was inoculated with a loopful of an $18 \mathrm{hr}$. tryptic digest broth culture of the strain to be tested. Several non-dependent, non-enhanced variants were tested in the same manner, as well as in streptomycin-free media for comparison. The tests were incubated and read at intervals (Table 4). Streptomycin in the concentrations used did not interfere with the coagulase activity of the $D$ and $E$ variants. Both produced firm plasma clots after 2-4 hr. incubation. Further incubation (24-72 hr.) of the coagulated plasma resulted in lysis of the clot.

The results of coagulase tests with non-dependent, non-enhanced isolates in streptomycin-free media were the same as those described for the $\mathbf{D}$ and $\mathbf{E}$ variants. However, in the presence of sub-inhibitory concentrations of strepto- 
mycin, clot formation was delayed, although not entirely inhibited; incubation for 12-24 hr. was required for the formation of a plasma clot (Table 4).

Table 4. Effect of streptomycin on coagulase activity of various strains of Staphylococcus aureus

\begin{tabular}{|c|c|c|c|c|c|c|c|}
\hline & & \multicolumn{6}{|c|}{ Period of incubation at $37^{\circ}(\mathrm{hr})}$. \\
\hline & $\begin{array}{l}\text { Streptomycin } \\
\text { sulphate } \\
\text { (mg./ml.) }\end{array}$ & \multicolumn{6}{|c|}{ Character of clot* } \\
\hline Dependent & $\begin{array}{c}25-0 \cdot 00005 \\
0\end{array}$ & $\mathbf{0}$ & $2+$ & $4+$ & $\begin{array}{l}4+ \\
\text { owth }\end{array}$ & & Lysed \\
\hline $\begin{array}{l}\text { Enhanced } \\
\text { Normal† }\end{array}$ & $\begin{array}{c}25-0 \cdot 00005 \\
0 \\
0 \cdot 5-0 \cdot 125 \\
0\end{array}$ & $\begin{array}{l}\mathbf{0} \\
\mathbf{0} \\
\mathbf{0} \\
\mathbf{0}\end{array}$ & $\begin{array}{l}\mathbf{2}+ \\
0 \\
0 \\
\mathbf{2}+\end{array}$ & $\begin{array}{l}4+ \\
2+ \\
0 \\
4+\end{array}$ & $\begin{array}{l}4+ \\
4+ \\
2+ \\
4+\end{array}$ & $\begin{array}{l}- \\
4+ \\
4+\end{array}$ & $\begin{array}{l}\text { Lysed } \\
\text { Lysed } \\
\text { Lysed } \\
\text { Lysed }\end{array}$ \\
\hline
\end{tabular}

\section{Morphology}

The colonial morphology of the original strain was that of the usual Staph. aureus; pigmentation was marked, and colonies were of uniform size and were non-haemolytic. The colonies of the $D$ and $E$ variants on tryptic digest agar containing streptomycin tended to be somewhat smaller and less pigmented than either those of normal isolates or of the $\mathbf{E}$ variant on streptomycin-free agar.

The cells of the normal isolates and the $\mathbf{E}$ variant were of characteristic staphylococcal morphology. However, smears of the $D$ variant always contained a few large, swollen cocci (Pl. 1, fig. 1). When transplanted to streptomycin-free tryptic digest agar and incubated 48-72 hr., a few colonies grew from heavy inocula. These were at first 'pin-point', but eventually matured into typical, deeply pigmented colonies $2-3 \mathrm{~mm}$. in diameter, composed entirely of large, swollen, yeast-like cocci not unlike the 'large bodies' produced by several species of bacillary cells (Dienes, 1939-47; Dienes \& Smith, 1944; Pl. 1, fig. 2).

When suitable agar block preparations were made and stained with methylene blue (Dienes \& Smith, 1944) these colonies of large cells could be seen developing on the streak completely surrounded or submerged by cells of normal morphology which appeared to be dead, since they did not develop into colonies (Pl. 1, fig. 3).

When a colony of these large cells was transplanted, and followed at frequent intervals by microscopic study of agar block preparations, the large cells were observed to divide by what appeared to be simple fission, eventually giving rise to normal staphylococci which were streptomycin susceptible or resistant, but no longer streptomycin dependent, and were otherwise identical with the parent culture (Pl. 1, figs. 4-7). 


\section{DISCUSSION}

Studies on the origin of bacterial resistance to penicillin (Demerec, 1945 a,b) indicate that differences in resistance can be explained by assuming the mutation of a number of equally important genes. Unlike penicillin resistance, which increases stepwise, and is partially dependent on selection, the appearance of streptomycin resistance (Demerec, 1948) seems to result from the mutation of genes of different potencies, thereby explaining the random appearance of progeny exhibiting various degrees of resistance to streptomycin. The extreme variability of streptomycin sensitivity exhibited by multiple fishings of the present strain of Staph. aureus both before and after initial exposure to streptomycin, is amenable to such an explanation.

The mechanism by which these variants of Staph. aureus utilize streptomycin has not been established. Dihydrostreptomycin is the only substance of those so far tested which could be substituted for streptomycin. It seems evident from the experimental results that the growth-stimulating factor is a moiety of streptomycin, rather than a trace contaminant. The inability of inactivated streptomycin to support or stimulate the growth of these variants suggests utilization of a molecular structure intimately related to the inhibiting properties of streptomycin.

If the individual characteristics of a given cell are considered as an expression of enzyme structure, then a change of cell character must reflect a change in enzyme structure. The ability to utilize streptomycin, or some moiety thereof then indicates the action of a new enzyme system. The concurrent loss of ability to grow in the absence of this new substrate further indicates the injury or loss of that system which previously had been utilized by the cell in obtaining from other sources that metabolite which must now be obtained in the whole or in part from streptomycin.

Itis well established that the capacity to elaborate enzymes under appropriate substrate stimulation, in yeasts at least, is gene determined and is inheritable in Mendelian patterns (Lindegren, 1945; Lindegren, Spiegelman \& Lindegren, 1944). If this basis for enzyme elaboration holds for Staph. aureus, the logical assumption then would be that streptomycin dependence, like streptomycin and penicillin resistance (Demerec, $1945 a, b, 1948$ ), is a potentiality. of a few individual cells in any large bacterial population. The spontaneous appearance of streptomycin-dependent variants in this strain of Staph. aureus can be explained readily on this basis, i.e. a rapidly mutating strain, a few cells of which carry a recessive gene determining the elaboration of an enzyme suitable for the utilization of streptomycin.

The significance of the pleomorphic changes reported here is not fully understood. However, the occurrence of similar morphological changes, appearing either spontaneously or in response to an altered environment in a number of different species of bacteria (Dienes, 1939-47) suggests a common cell mechanism, whether such phenomena are regarded as simple response to injury or as representing something more fundamental to the continued growth and survival of the cell. The appearance of pleomorphic change in a few cells 
when large inocula of this strain were transplanted to streptomycin-free agar, concurrent with the disappearance of streptomycin dependency suggests a relationship between morphological variation and mutation.

The substance of this paper was presented in part at the first meeting of the North-east Branch, Society of American Bacteriologists, on 11 February 1949 at Cambridge, Massachusetts.

The work was supported in part by a grant from The Grant Foundation Inc.

\section{REFERENCES}

AGNew, S., KAPLAN, M. \& SpinK, W. W. (1947). Comparative inhibitory effect of penicillin and streptomycin upon the action of staphylocoagulase. Proc. Soc. exp. Biol., N.Y., 65, 38.

Bartz, Q. R., Controulis, J., Crooks, H. M. jr. \& Rebstock, M. C. (1946). Dihydrostreptomycin. J. Amer. chem. Soc. 68, 2168.

Bondr, A. jr. \& Dietz, C. C. (1944). Production of penicillinase by bacteria. Proc. Soc. exp. Biol., N.Y., 56, 132.

Demerec, M. (1945a). Production of Staphylococcus strains resistant to various concentrations of penicillin. Proc. nat. Acad. Sci., Wash., 31, 16.

Demerec, M. (1945 b). Genetic aspects of changes in Staphylococcus aureus producing strains resistant to various concentrations of penicillin. Ann. Mo. bot. Gdn, 32, 181.

Demerec, M. (1948). Origin of bacterial resistance to antibiotics. J. Bact. 56, 63.

Denkeiwater, R., Cook, M. A. \& Tishler, M. (1945). Effect of cysteine on streptomycin and streptothricin. Science, 102, 12.

Dienes, L. (1939 a). L type variant forms in cultures of various bacteria. Proc. Soc. exp. Biol., N.Y., 42, 636.

Dienes, L. (1939b). A peculiar reproductive process in colon bacillus colonies. Proc. Soc. exp. Biol., N.Y., 42, 773.

Dienes, L. (1942). The significance of large bodies and development of $L$ type of colonies in bacterial cultures. J. Bact. 44, 37.

Dienes, L. (1944). L type of growth in cultures of haemolytic parainfluenza bacillus. Proc. Soc. exp. Biol., N.Y., 55, 142.

Dienes, L. (1946). Reproductive processes in Proteus cultures. Proc. Soc. exp. Biol., N.Y., 63, 265.

Dienes, $\mathbf{L}$. (1947). Isolation of pleuropneumonia-like organisms from cultures of H. influenzae. J. Bact. 54, 3.

DrEnes, L. \& SMTTH, W. E. (1944). The significance of pleomorphism in Bacteroides strain. J. Bact. 48, 125.

Dugan, B. M. (1948). Aureomycin-a new antibiotic. Ann. N.Y. Acad. Sci. 51, 177 .

Johnson, B. A., Anker, H. \& Meleney, F. L. (1945). Bacitracin; a new antibiotic produced by a member of the $B$. subtilis group. Science, 102, 376 .

Lindegren, C. C. (1945). Mendelian and cytoplasmic inheritance in yeasts. Ann. Mo. bot. Gdn, 32, 107.

Lindegren, C. C., Spiegelman, S. \& Lindegren, G. (1944). Mendelian inheritance of adaptive enzymes in yeast. Proc. nat. Acad. Sci., Wash., 30, 346.

Price, C. W., Nielsen, J. K. \& Wexch, H. (1946). Estimation of streptomycin in body fluids. Science, 103,56 .

Rake, G. \& Donovick, R. (1946). Procedure for testing sterility of concentrated streptomycin solutions. Proc. Soc. exp. Biol., N.Y., 62, 31. 


\section{EXPLANATION OF PLATE}

Fig. 1. Smear from unselected colony, original $24 \mathrm{hr}$. blood agar plate. Methylene blue; $\times 1300$. Note few large, swollen cocci.

Fig. 2. Smear from $72 \mathrm{hr}$. streptomycin-free tryptic digest agar plate streaked with $D$ variant. Gram stain; $\times 1500$. Note size of cocci and dividing cells.

Fig. 3. Agar block preparation from $24 \mathrm{hr}$. streptomycin-free tryptic digest agar plate streaked with $D$ variant. Methylene blue; $\times 1500$. Note large, swollen cocci on agar among normal cocci. Notice cell wall of some of the larger cocci.

Fig. 4. Agar block preparation from $48 \mathrm{hr}$. streptomycin-free tryptic digest agar plate streaked with $D$ variant. Methylene blue; $\times 1500$. Normal cocci have almost completely disappeared.

Fig. 5. Impression preparation, made from same plate illustrated in fig. 4. Methylene blue; $\times 1500$.

Fig. 6. Agar block preparation, edge of colony on plate illustrated in fig. 4. Methylene blue; $\times 1500$. Note large, swollen cocci dividing by fission.

Fig. 7. Impression preparation from $24 \mathrm{hr}$. blood agar plate planted with colonies illustrated in fig. 3. Methylene blue; $\times \mathbf{1 3 0 0}$. Note reappearance of normal morphology and a few remaining large, swollen cocci, some of which are dividing.

(Received 11 June 1949) 
Journal of General Microbiology, Vol. 4, No. 2
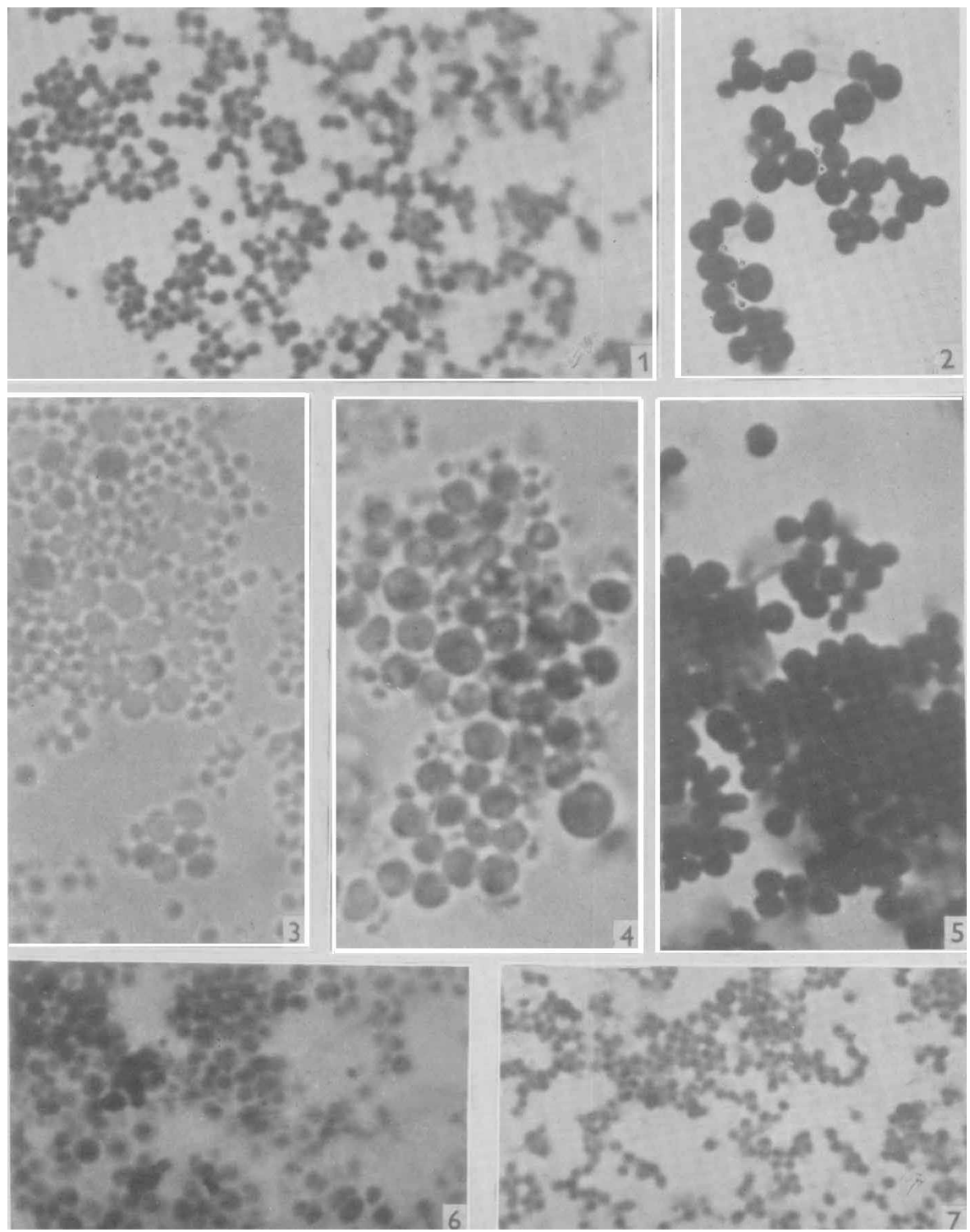

Figs. 1-7

G. F. Foley \& H. Shwachman-Streptomycin dependence in Staph. aureus. Plate 1 